\title{
Household Size and the Decision to Purchase Health Insurance in Cambodia: Results of a Discrete-Choice Experiment with Scale Adjustment
}

\author{
Sachiko Ozawa ${ }^{1} \cdot$ Simrun Grewal $^{2} \cdot$ John F.P. Bridges ${ }^{1,3}$
}

Published online: 10 February 2016

(c) The Author(s) 2016. This article is published with open access at Springerlink.com

\begin{abstract}
Background Community-based health insurance (CBHI) schemes have been introduced in low- and middle-income countries to increase health service utilization and provide financial protection from high healthcare expenditures.

Objective We assess the impact of household size on decisions to enroll in CBHI and demonstrate how to correct for group disparity in scale (i.e. variance differences).

Methods A discrete choice experiment was conducted across five CBHI attributes. Preferences were elicited through forced-choice paired comparison choice tasks designed based on D-efficiency. Differences in preferences were examined between small (1-4 family members) and large (5-12 members) households using conditional logistic regression. Swait and Louviere test was used to identify and correct for differences in scale.

Results One-hundred and sixty households were surveyed in Northwest Cambodia. Increased insurance premium was associated with disutility [odds ratio (OR) $0.61, p<0.01$ ],
\end{abstract}

Electronic supplementary material The online version of this article (doi:10.1007/s40258-016-0222-9) contains supplementary material, which is available to authorized users.

Sachiko Ozawa

ozawa@jhu.edu

1 Department of International Health, Johns Hopkins Bloomberg School of Public Health, 615 N. Wolfe Street, Baltimore, MD 21205, USA

2 Department of Pharmacy, Pharmaceutical Outcomes Research and Policy Program, University of Washington, 1959 NE Pacific Street, Health Sciences Building, Room H-375, Seattle, WA 98195, USA

3 Department of Health Policy and Management, Johns Hopkins Bloomberg School of Public Health, 624 N. Broadway, Hampton House 689, Baltimore, MD 21205, USA while significant increase in utility was noted for higher hospital fee coverage (OR 10.58, $p<0.01$ ), greater coverage of travel and meal costs (OR 4.08, $p<0.01$ ), and more frequent communication with the insurer (OR 1.33, $p<0.01$ ). While the magnitude of preference for hospital fee coverage appeared larger for the large household group (OR 14.15) compared to the small household group (OR $8.58)$, differences in scale were observed $(p<0.05)$. After adjusting for scale $(k$, ratio of scale between large to small household groups $=1.227,95 \%$ confidence interval 1.002-1.515), preference differences by household size became negligible.

Conclusion Differences in stated preferences may be due to scale, or variance differences between groups, rather than true variations in preference. Coverage of hospital fees, travel and meal costs are given significant weight in CBHI enrollment decisions regardless of household size. Understanding how community members make decisions about health insurance can inform low- and middle-income countries' paths towards universal health coverage.

\section{Key Points for Decision Makers}

Coverage of hospital fees, travel and meal costs were given the most weight in decisions to enroll in community-based health insurance in Cambodia.

Scale was observed where respondents answered differently between small and large household groups.

Stated preferences for health insurance do not appear to differ by household size after adjusting for scale.

The impact of scale should be examined when analyzing differences in preferences across groups. 


\section{Introduction}

In efforts to reduce out-of-pocket payments and prevent healthcare driven poverty, several low- and middle-income countries have introduced community-based health insurance (CBHI) schemes to increase health service utilization and provide financial protection from high healthcare expenditures [1-3]. However, gaps remain in insurance enrollment and service utilization, where the impact of household size has been debated. A recent study assessing equity of insurance enrollment in Ghana found that larger households were less likely to be enrolled in health insurance plans [4]. Empirical evidence also suggests that an unmet need for healthcare services increases with household size [5]. In investigating consumer preferences and the decision to enroll in CBHI in Burkina Faso, authors found that household size served as a possible obstacle to enrollment, with study respondents from large households describing the financial burden of insuring all household members [6]. The impact of household size on insurance enrollment can be particularly important as poorer, rural regions also tend to have higher numbers of household members. In order to understand the potential contribution of household size to health insurance enrollment decisions, we examined health insurance attribute preferences on the basis of household size.

Many factors can influence the decision to enroll in health insurance including: affordability, risk preference, quality of care, level of information about health insurance, social capital and accessibility [7-11]. More generally, theoretical models predict that enrollment in voluntary health insurance occurs when enrollees are confident they are getting "value for their money" [12]. However, studies related to health insurance enrollment often focus on the role of premium prices [13-15]. While premiums undoubtedly play a direct role in health insurance affordability, various attributes impact health service utilization behavior and the valuation of and subsequent decision to enroll in health insurance [16, 17]. For example, a study in Nigeria found that while the cost of direct medical care was of key concern to individuals in the country, the distance to a facility and associated expenditures, such as transportation, were also considered as impediments [18]. In Malawi, researchers found relative importance of attributes ordered as transport, health services benefits, enrollment unit, premium, copayment and management [19]. Health insurance attributes may address various barriers or deterrents associated with seeking healthcare.

Healthcare financing mechanisms are of critical importance in Cambodia where high household healthcare expenditures place a large burden on poor families and have been noted as a major cause of poverty in the country
$[20,21]$. Estimates for out-of-pocket expenditures place the amount at two-thirds of all healthcare spending in Cambodia or around US $\$ 45$ per capita as of 2013, compared to total healthcare spending of around US\$76 per capita or $7.5 \%$ of GDP per capita [22]. The burden of out-of-pocket expenditures becomes particularly important when considering that $41 \%$ of Cambodia's population lives on less than US $\$ 2.00$ per day at 2005 international prices [23]. Community-based health insurance (CBHI) began operating in Cambodia in 1998 alongside microcredit mechanisms and health equity funds $[15,24,25]$.

One of the CBHI schemes relevant for this study had been in operation since 2005 by Cambodian Association for Assistance to Families and Widows (CAAFW) in two Operational Districts in Northwest Cambodia. At the time of the study, the health insurance enrolled families were charged US\$2 per family member per year and up to US $\$ 12$ per family per year. CAAFW was frequently asked to provide people with premium installments for seasonal income fluctuations and make visits across villages to advocate for patients' wellbeing. While this scheme reported enrollment rates of $21 \%$ of the target population in 2011 [26], coverage through CBHI remained low nationwide, covering less than $1 \%$ of the total Cambodian population [2]. This may be due to supply-side challenges of nationally scaling up community-based schemes, focus on social health insurance for formal sector employees, and demand-side difficulties to encourage uptake in voluntary schemes. Consideration of individuals' decisions to participate in health insurance remains critical to improving enrollment in voluntary health insurance schemes.

Discrete choice experiments (DCE) can help one understand how individuals place relative value on health insurance attributes by eliciting stated preferences [27-29]. While DCE studies have been increasingly applied to study health insurance in high-income countries [30-32], a significant gap remains to understand health insurance preferences in low- and middle-income settings [19, 33]. Current literature establishes that enrollment decisions for health insurance occur in accordance with individual preferences around premium level, degree of cost-sharing, and inclusion of additional benefits such as coverage of travel expenses [19, 34-36]. This research aims to examine health insurance preferences beyond premium, by understanding the role of several health insurance attributes and investigate how stated preferences differ if the respondent is from a small household (1-4 household members) versus a large household (5-12 household members).

This study also makes a methodological contribution by assessing the impact of scale on preference differences between household size groups. Scale, which relates inversely to variance, reflects the degree to which the random component of utility modeled in a DCE is 
correlated with household size, the covariate of interest [37]. Variance differences may exist across two groups due to one group being more specific and vocal about their likes and dislikes and expressing them more clearly, accurately and strongly on the DCE survey. It may also come about when one group does not pay as close attention to the attributes presented to them and tends to pick responses more randomly or haphazardly. We illustrate the impact of scale adjustment in this DCE analysis to better understand the impact of household size on health insurance enrollment decisions.

\section{Methods}

Key attributes of CBHI and their respective levels were identified from previous qualitative and quantitative studies in Northwest Cambodia [24, 38, 39]. Specifically, focus groups conducted across CBHI enrollment status groups (currently enrolled, formerly enrolled, or never enrolled individuals) revealed attributes that were commonly described as being important in people's decisions to enroll in CBHI schemes. These attributes included: premium price per capita, premium payment frequency, coverage of hospital fee costs, coverage of travel and meal costs, and frequency of communication with the insurer. These five attributes were the most frequently discussed in focus groups about the CBHI scheme and areas where policy options were available to elicit people's preferences. For example, premium payment frequency asked whether people preferred an annual payment or bi-annual installments. Greater visits and visibility of the insurer was seen as a benefit for people to build greater trust in the CBHI organization. The DCE survey used these five attributes with two levels each (except for premium price which contained five levels for greater delineation). The levels for each attribute represent the ranges of responses found across the population based on a previous household survey [39]. Table 1 details the attributes, their descriptions, and respective levels utilized in the DCE survey.

Ten versions of the DCE survey, each version with nine tasks, were administered in pen and paper in 2010. For each choice task, the survey asked which CBHI plan the respondent preferred (see Electronic Supplementary Material). Preferences were elicited through forced-choice paired comparison choice tasks designed based on D-efficiency using the Sawtooth Software (strength of design: 810). An opt-out question was not included as the study focused on how health insurance benefits could be improved for the community rather than market decisions on whether or not people will obtain health insurance. An example task is provided in Fig. 1. The DCE survey was administered among heads of households or their spouses in ten randomly selected villages in the Thmar Pouk and Svey Chek Operational Districts in Banteay Meanchey Province of Cambodia. This area was selected as a CBHI scheme was operated by CAAFW at the time of the study. Five villages in each Operational District were chosen with variation in both village size and distance to the nearest health center. The DCE study was conducted among 160 individuals through a cluster random sample (16 individuals per village) where eligible households were enrolled in the study regardless of household size. While the minimum required sample size for a DCE depends on a number of criteria [40], this sample size was within the range of sample sizes observed in most published studies [41]. Households were defined as those living under the same roof for the majority of the year and sharing meals together. This definition was also used by the health insurer. The CBHI plan required that households enroll as a unit to avoid adverse selection. Categorization of small (1-4) and large (5-12) households were based on the average household size of 4.7 from previous studies in the region [38]. The survey included background information on the

Table 1 Discrete choice experiment attributes and levels

\begin{tabular}{|c|c|c|}
\hline Attributes & Description & Levels \\
\hline Premium price & $\begin{array}{l}\text { This is how much money you pay for health insurance. The listed price is for one person in your } \\
\text { family per year. If you buy health insurance, you have to enroll everyone in your family. For } \\
\text { example, if you have } 4 \text { people in your family and it costs US } \$ 2.0 / \text { person/year, then it will cost } \\
\text { US } \$ 8.0 \text { for your family per year }\end{array}$ & $\begin{array}{l}\text { US } \$ 1.5, \text { US } \$ 2, \\
\text { US } \$ 2.5 \text {, US } \$ 3 \text {, } \\
\text { US } \$ 4\end{array}$ \\
\hline $\begin{array}{l}\text { Payment } \\
\text { frequency }\end{array}$ & $\begin{array}{l}\text { This is when you pay for health insurance. You can pay altogether once a year or you can pay half the } \\
\text { amount twice a year }\end{array}$ & Once; twice \\
\hline $\begin{array}{l}\text { Hospital fee } \\
\text { coverage }\end{array}$ & This is how much you pay at the referral hospital. You can pay nothing, or pay $20 \%$ of the costs & Pay $20 \%$; free \\
\hline $\begin{array}{l}\text { Travel/meal } \\
\text { coverage }\end{array}$ & $\begin{array}{l}\text { This is whether the health insurance would cover your initial travel to the health center or referral } \\
\text { hospital and for meals for your family members. You can have this covered by health insurance or } \\
\text { not }\end{array}$ & $\begin{array}{l}\text { Not covered; } \\
\text { covered }\end{array}$ \\
\hline $\begin{array}{l}\text { Communication } \\
\text { frequency }\end{array}$ & $\begin{array}{l}\text { This is how often you can communicate each year with the community-based organization that } \\
\text { operates health insurance. You can communicate once or twice a year, or three to five times a year }\end{array}$ & $\begin{array}{l}1-2 \text { times; } 3-5 \\
\text { times }\end{array}$ \\
\hline
\end{tabular}


Fig. 1 Example discrete choice experiment choice task

\begin{tabular}{|l|c|c}
\hline Attributes & Plan A & Plan B \\
\hline Premium & $\$ 2.5$ & $\$ 3.0$ \\
\hline Timing of Payment & Twice & Once \\
\hline Hospital Costs & Pay 20\% & Free \\
\hline Travel and Meal Costs & Not covered & Covered \\
\hline Communication with Insurer & $1-2$ times/year & $3-5$ times/year \\
\hline Choice & $\square$ & $\square$
\end{tabular}

respondent as well as the choice tasks. The survey was conducted in Khmer and was pre-tested and back translated. The study was approved by the Institutional Review Boards of Johns Hopkins School of Public Health and the National Ethics Committee for Health Research in Cambodia.

\subsection{Analytic Model}

The random utility model was used to structure an analysis consisting of a deterministic component and random component [42]. The deterministic component $v$ reflects utility shifts as a result of observable factors, which were the five CBHI attributes included in DCE choice tasks [premium price $(P P)$, frequency of premium payment $(F)$, coverage of hospital fees $(H)$, coverage of travel and meal costs $(T)$, and frequency of communication with the insurer $(C)]$. The random component of utility encapsulates the unknown characteristics of the decision maker and their choice options as a random variable. The probability $P$ that an individual $i$ chooses an insurance option $n$ among a choice set $j$ given its specified attributes was modeled using McFadden's conditional logit model [43].

$P_{\text {in }}=\frac{\exp \left[v_{\text {in }}\left(\mathrm{PP}_{\mathrm{in}}, F_{\mathrm{in}}, H_{\mathrm{in}}, T_{\mathrm{in}}, C_{\mathrm{in}}\right)\right]}{\sum_{j=1}^{J} \exp \left[v_{\mathrm{ij}}\left(\mathrm{PP}_{\mathrm{ij}}, F_{\mathrm{ij}}, H_{\mathrm{ij}}, T_{\mathrm{ij}}, C_{\mathrm{ij}}\right)\right]}$

Empirical specifications of the model allows us to calculate the marginal utility of each health insurance attribute, represented by the coefficients derived from the conditional logit regression.

We aimed to obtain estimates for: (1) the marginal utility of each health insurance attribute for the full study population, and (2) determine if marginal utility calculations differ significantly on the basis of household size (small or large households). Comparison groups based on small (1-4 members) and large (5-12 members) household size were generated utilizing a transformation matrix of DCE survey responses. Price of the health insurance premium was treated as a linear function, and not as a categorical price attribute for ease of interpretation. The base case for the four binary attributes were: once for payment frequency, pay $20 \%$ for hospital costs, not covered for travel and meal costs, and 1-2 times/year for communication with insurer. We illustrate the results with and without payment frequency as some respondents may have misinterpreted the question to imply an increase in total premium rather than more frequent payments. A conditional logit model was developed using STATA (Stata Corporation 2010), followed by Wald tests for assessment of coefficients differences by household size.

\subsection{Analysis of Scale}

The conditional logit model coefficients capture two sources of potential difference between small and large households: (1) genuine preference differences for health insurance attributes and (2) differences in how individuals from various groups attenuate to choice tasks. The effects of these two potential sources of differentiation were assessed according to methodology described by Swait and Louviere [37]. This methodology evaluates if true preference differences exist between small and large household groups and whether or not there is a significant impact of scale. In the context of conditional logit choice models, scale relates inversely to response data variance and signifies differences in how groups may respond to choice tasks. In testing for an effect of scale, we looked for a relationship between small and large household preferences by observing one group's conditional logit coefficient values as a scaled factor of the other.

Building on the random utility model, the scale parameter acts as a scalar applied to an individual's probabilistic choice, resulting in a model adjustment where $\mu$ represents a scalar constant and $\beta$ represents the marginal utility related to each attribute:

$P_{\text {in }}=\frac{\exp \left[\mu \beta_{\text {in }}\left(\mathrm{PP}_{\mathrm{in}}, F_{\mathrm{in}}, H_{\mathrm{in}}, T_{\mathrm{in}}, C_{\mathrm{in}}\right)\right]}{\sum_{j=1}^{J} \exp \left[\mu \beta_{\mathrm{ij}}\left(P P_{\mathrm{ij}}, F_{\mathrm{ij}}, H_{\mathrm{ij}}, T_{\mathrm{ij}}, C_{\mathrm{ij}}\right)\right]}$

Unlike regular stated preference models that assume scalar $\mu$ to be 1 or equal between study subgroups, a relative scale factor $k$ was considered representing the ratio of scale between household size groups. The value of the scale parameter $k$ was assessed according to the following procedure [37]: 
1. An appropriate range of $k$ was determined by taking the ratios of conditional logit regression coefficients in large to small households. The scale parameter range was refined to obtain more accurate estimates.

2. Within the estimated range of $k, 100$ finite values of the scale parameter were defined at equal intervals. For each value of $k$, a new data set was created which applied the specified scalar to the transformed matrix data for small households. For each adjusted dataset, we obtained the log likelihood for the conditional logit regression applied to the entire study population (which combined adjusted data for small households and original data for large households).

3. We generated a plot of log likelihoods relative to $k$ and identified the maximum $\log$ likelihood value and corresponding scale parameter value.

4. A $95 \%$ confidence interval was calculated around the point estimate of $k$ to determine if the value of $k$ differs significantly from 1 .

This methodology essentially generated a new dataset without the impact of scale that could be compared with the original data. By correcting for scale, which is related to the inverse of variance, we can isolate true preference differences for health insurance attributes from differences in how groups respond to choice tasks. To observe the impact of scale, we graph the conditional logit coefficients to provide a visual comparison of coefficient values before and after correction for scale.

\section{Results}

The DCE survey was conducted across 160 household respondents in Northwest Cambodia. Table 2 presents descriptive statistics of the DCE survey by respondents' household size. We found small and large household groups to be balanced on many characteristics. The sample was split evenly where 80 households had between 1-4 household members while another 80 households had between 5-12 household members. Percentage of female respondents was comparable between the two groups $(p=0.74)$ and the average school years were near 3.1 years for both household size classifications $(p=0.98)$. Although enrollment status in health insurance may be considered a potential confounder in the study design,
Table 2 Descriptive statistics of survey population by household size

\begin{tabular}{|c|c|c|c|c|}
\hline Characteristic & $\begin{array}{l}\text { Total survey } \\
\text { population }\end{array}$ & $\begin{array}{l}\text { Small households } \\
\text { (1-4 people) }\end{array}$ & $\begin{array}{l}\text { Large households } \\
\text { (5-12 people) }\end{array}$ & $p$ value \\
\hline Sample size (no.) & 160 & 80 & 80 & \\
\hline \multicolumn{5}{|l|}{ Location (no.) } \\
\hline Thmar Pouk & 75 & 32 & 43 & \multirow[t]{2}{*}{0.081} \\
\hline Svay Chek & 85 & 48 & 37 & \\
\hline Average age (years) & 41.1 & 39.1 & 43.1 & $0.028^{*}$ \\
\hline \multicolumn{5}{|l|}{ Gender (no.) } \\
\hline Female & 100 & 49 & 51 & \multirow[t]{2}{*}{0.744} \\
\hline Male & 60 & 31 & 29 & \\
\hline Average schooling (years) & 3.1 & 3.1 & 3.1 & 0.976 \\
\hline \multicolumn{5}{|l|}{ Insurance status (no.) } \\
\hline Never enrolled & 60 & 28 & 32 & \multirow[t]{4}{*}{0.130} \\
\hline Previously enrolled & 25 & 14 & 11 & \\
\hline Enrolled (<12 months) & 11 & 9 & 2 & \\
\hline Enrolled ( $\geq 12$ months) & 64 & 29 & 35 & \\
\hline \multicolumn{5}{|c|}{ Social economic status quintile (no.) } \\
\hline 1st (poorest) & 28 & 11 & 17 & \multirow[t]{5}{*}{$0.014 *$} \\
\hline 2nd & 35 & 11 & 24 & \\
\hline $3 \mathrm{rd}$ & 16 & 9 & 7 & \\
\hline 4 th & 44 & 23 & 21 & \\
\hline 5th (wealthiest) & 37 & 26 & 11 & \\
\hline \multicolumn{5}{|l|}{ Insurance knowledge (no.) } \\
\hline Nothing & 14 & 10 & 4 & \multirow[t]{4}{*}{0.255} \\
\hline A little & 33 & 14 & 19 & \\
\hline Some & 55 & 25 & 30 & \\
\hline A lot & 58 & 31 & 27 & \\
\hline
\end{tabular}


health insurance enrollment status and insurance knowledge was not significantly different between small and large household groups ( $p=0.13$ and $p=0.26$, respectively). The only differences found were for age $(p=0.03)$ and socioeconomic status $(p=0.01)$ where smaller households had younger and wealthier respondents.

\subsection{Health Insurance Preferences}

A conditional logit model was developed with coefficients for each health insurance attribute for the entire sample, and by household size (Table 3). Examining the magnitude of model coefficients across the full sample, hospital fee coverage (a change from $20 \%$ cost sharing to full coverage) led to the largest observed impact on choice of health insurance, followed by travel and meal coverage, premium price, and communication with insurer in descending order. Significant disutility was found with increasing premium price (OR 0.61, $p<0.01$ ). The largest increase in utility was noted for hospital fee coverage, changing from the base case of a respondent paying $20 \%$ of hospital fees to free $(0 \%)$ hospital care (OR 10.58, $p<0.01)$. Travel and meal costs exhibit the same trend, but to a lesser magnitude (OR 4.08, $p<0.01$ ). The coefficient for communication frequency with the insurer conveyed a smaller but significant positive change in utility as communication increased from the base case of 1-2 time/year to 3-5 times per year (OR 1.33, $p<0.01$ ). There was no significant preference elicited between payment frequency of once or twice for the total survey population (OR $0.95, p=0.52$ ). Figure 2 conveys these trends by estimating the mean predicted probability that a health insurance option would be selected after changing noted attribute levels holding all other levels constant across premium price values.

Analyzing the data by household size, coefficient trends mostly reflected those of the total survey population, with a few noted differences. While the point estimates of the coefficients indicate that the order of importance for the five attributes (as reflected by the magnitude of their respective coefficients) mirrors that of the total survey population, the magnitude and associated variance of the effects were larger for the large household group than the small household group. For example, hospital fee coverage observed a nearly significant difference, with large households experiencing a greater marginal utility from increased hospital fee coverage (OR 14.15) than small households (OR 8.58). Similarly, travel and meal coverage appeared to have higher marginal utility among large households (OR 5.21) compared to small households (OR 3.46) although Wald tests indicated no statistically significant differences. Since payment frequency was found to not have a significant impact on insurance plan choice and

Table 3 Conditional logistic regression of survey population by household size

\begin{tabular}{|c|c|c|c|c|c|c|c|c|c|c|}
\hline \multirow[t]{2}{*}{ Attribute } & \multicolumn{3}{|c|}{ Total survey population } & \multicolumn{3}{|c|}{ Small households (1-4 people) } & \multicolumn{3}{|c|}{ Large households (5-12 people) } & \multirow{2}{*}{$\begin{array}{l}\text { Wald } \\
\text { test } \\
p \text { value }\end{array}$} \\
\hline & $\begin{array}{l}\text { Odds } \\
\text { ratio }\end{array}$ & Coeff. [SE] & $p$ value & $\begin{array}{l}\text { Odds } \\
\text { ratio }\end{array}$ & Coeff. [SE] & $p$ value & $\begin{array}{l}\text { Odds } \\
\text { ratio }\end{array}$ & Coeff. [SE] & $p$ value & \\
\hline \multicolumn{11}{|c|}{ Model 1: all attributes ${ }^{\dagger}$} \\
\hline Premium price & 0.608 & $-0.497[0.075]$ & $<0.001 *$ & 0.633 & $-0.458[0.098]$ & $<0.001 *$ & 0.572 & $-0.559[0.118]$ & $<0.001 *$ & 0.513 \\
\hline $\begin{array}{l}\text { Payment } \\
\text { frequency }\end{array}$ & 0.945 & $-0.057[0.089]$ & 0.523 & 0.922 & $-0.081[0.123]$ & 0.514 & 0.969 & $-0.032[0.131]$ & 0.805 & 0.788 \\
\hline $\begin{array}{c}\text { Hospital fee } \\
\text { coverage }\end{array}$ & 10.580 & $2.359[0.129]$ & $<0.001^{*}$ & 8.585 & $2.150[0.160]$ & $<0.001 *$ & 14.154 & $2.650[0.220]$ & $<0.001^{*}$ & 0.065 \\
\hline $\begin{array}{c}\text { Travel/meal } \\
\text { coverage }\end{array}$ & 4.084 & $1.407[0.124]$ & $<0.001 *$ & 3.456 & $1.240[0.154]$ & $<0.001^{*}$ & 5.207 & $1.650[0.212]$ & $<0.001 *$ & 0.119 \\
\hline $\begin{array}{l}\text { Communication } \\
\text { frequency }\end{array}$ & 1.334 & $0.288[0.089]$ & $0.001 *$ & 1.256 & $0.228[0.123]$ & 0.062 & 1.433 & $0.360[0.131]$ & $0.006^{*}$ & 0.464 \\
\hline \multicolumn{11}{|c|}{ Model 2: without payment frequency } \\
\hline Premium price & 0.610 & $-0.495[0.075]$ & $<0.001^{*}$ & 0.631 & $-0.460[0.098]$ & $<0.001^{*}$ & 0.574 & $-0.555[0.117]$ & $<0.001 *$ & 0.531 \\
\hline $\begin{array}{l}\text { Hospital fee } \\
\text { coverage }\end{array}$ & 10.454 & $2.347[0.127]$ & $<0.001 *$ & 8.457 & $2.135[0.157]$ & $<0.001 *$ & 14.027 & $2.641[0.216]$ & $<0.001 *$ & 0.058 \\
\hline $\begin{array}{c}\text { Travel/meal } \\
\text { coverage }\end{array}$ & 4.039 & $1.396[0.122]$ & $<0.001 *$ & 3.411 & $1.227[0.152]$ & $<0.001 *$ & 5.155 & $1.640[0.209]$ & $<0.001 *$ & 0.109 \\
\hline $\begin{array}{l}\text { Communication } \\
\text { frequency }\end{array}$ & 1.310 & $0.270[0.084]$ & $0.001 *$ & 1.223 & $0.201[0.115]$ & 0.080 & 1.420 & $0.351[0.125]$ & $0.005^{*}$ & 0.378 \\
\hline
\end{tabular}


Fig. 2 Mean predicted probabilities of selection based on community-based health insurance (CBHI) attributes
Fig. 3 Plot to determine the value of scale parameter $k$

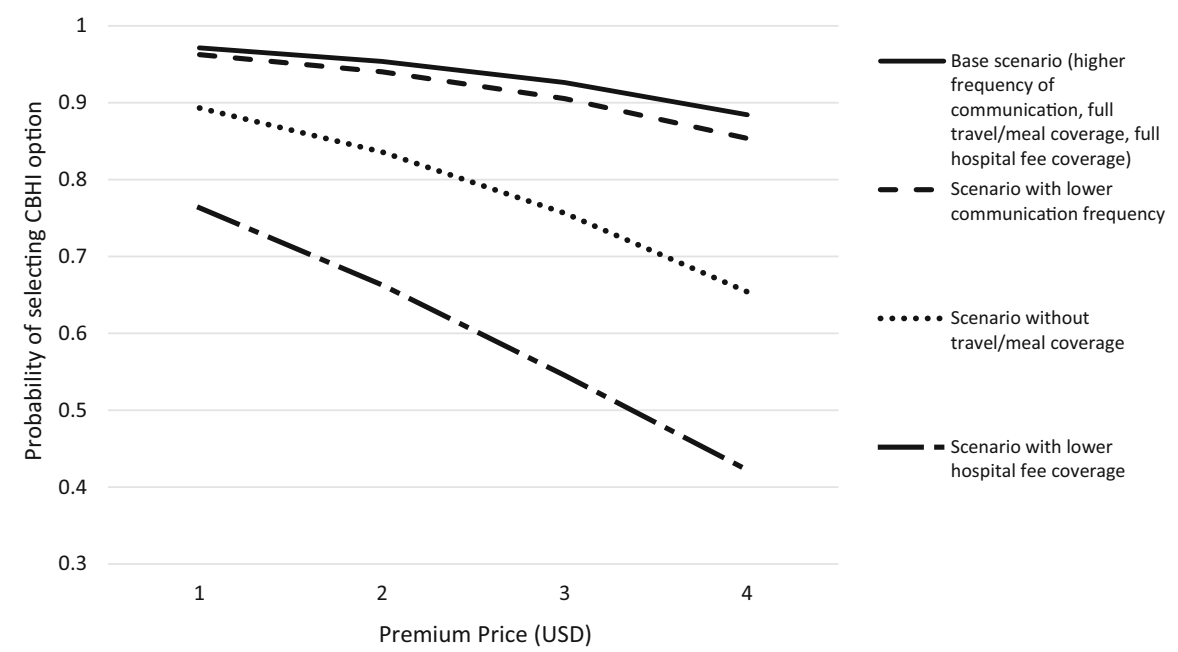

Note: Although the DCE survey only included five premium price levels, we estimated continuous average predicted probabilities based on conditional logistic regression results.

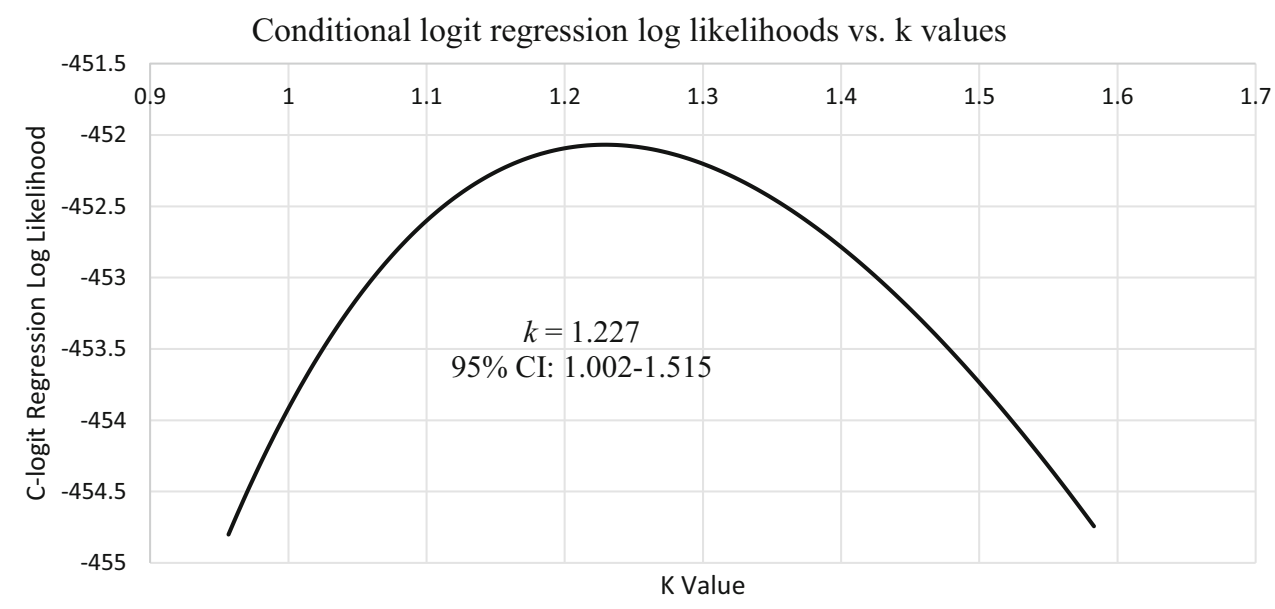

Note: $\mathrm{k}$ is the scale factor representing the ratio of scale between large to small households. due to concerns about some respondents misinterpreting this choice, further analysis of scale parameter did not include this attribute.

\subsection{Scale Parameter Results}

We estimated the scale parameter $k$ at 1.227 (95\% CI: 1.002-1.515), which represent the ratio of scale between small and large households. The likelihood ratio test revealed that this scale parameter differs significantly from 1 , where a difference in variance was observed between the two household size groups $(p<0.05)$. Figure 3 depicts the $\log$ likelihood values of the conditional logit model corresponding to each specified value of the scale parameter.

The Swait and Louviere test confirmed that there are no significant differences in preferences overall between small and large household size across all attributes $(p>0.05)$ after accounting for scale. Therefore, we concluded that any differences in conditional logit coefficient values between large and small households result from a significant effect of scale. When response data are adjusted by the derived scale parameter, the bias introduced by differences in task attenuation is eliminated (Fig. 4).

\section{Discussion}

This study demonstrates that the composition of a CBHI plan benefit package, such as coverage of hospital fee, travel and meal costs, has a strong impact on an individual's choice of health insurance, followed by premium price, and communication with the insurer. Preferences for a better benefit package including coverage of costs of travel and meals were much stronger than considerations 


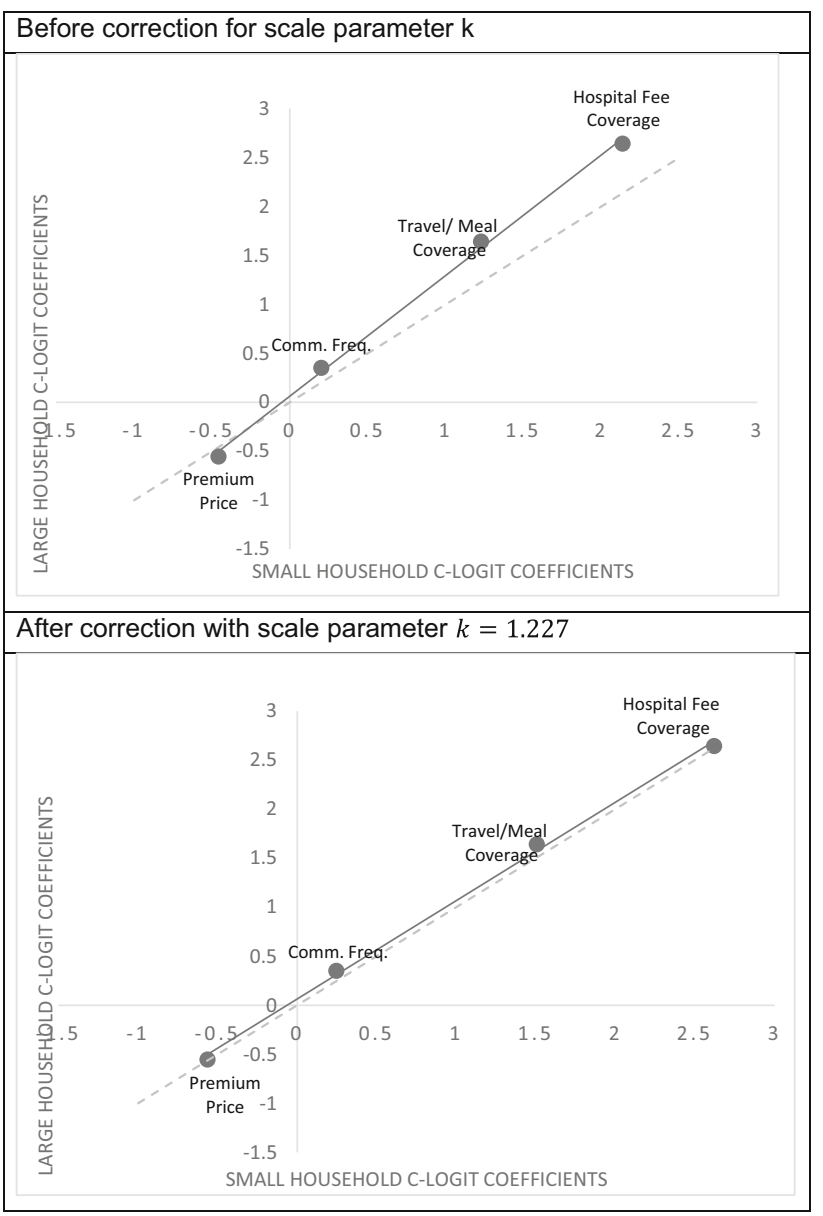

Note: When there is no impact of scale, the plotted line would have a slope of 1 (the dashed line).

Fig. 4 Visual comparison of coefficient values by household size: fit before and after correction for scale

around costs. This finding remains consistent with current literature which highlights various considerations made in enrollment decisions beyond premium price, including the importance of expanded benefits such as travel and meal costs $[4,7,19]$. By understanding the relative importance and effect sizes of health insurance characteristics, policy makers can inform resource allocation decisions by targeting benefits that have the greatest influence on individual choice.

While initial examination of preference differences by household size showed a larger effect across all attributes among larger households, this effect disappeared after controlling for scale. This finding of a significant scale effect between household size groups suggests that differences in characteristics of two populations could affect DCE task performance, irrespective of differences in preferences. The existence of scale suggests that large households may have paid less attention to the DCE tasks or smaller households may have been more attuned to their preferences. While additional qualitative research is necessary to further understand true preference differences, one hypothesis is that the differences in propensity to answer or attenuate to questions among the two groups may be related to the observation that respondents from smaller households were younger and wealthier in the study. Further quantitative research could also be valuable in validating the scale factor.

This research highlights the critical importance of assessing and adjusting for scale in DCE analyses. Examination of scale lends power to distinguishing true preference differences when differential variance is observed between groups. This study supports the recommendations to isolate the effect of scale prior to comparing preferences across groups, as differences in stated preferences may be due to scale rather than true variations in preferences [44]. Controlling for scale could remove confounding due to differences in ability to respond to DCE choice tasks.

There are notable limitations in the design of the DCE study. First, stated preferences are subject to hypothetical bias and may not actually be seen in the context of empirical choice, thereby making these choices more conceptual. Second, while the DCE survey was pre-tested in the region and back-translated for validity, the choice set was not tested for cognitive understanding in a population with low literacy rates. Third, the attributes in the choice set were obtained from previous qualitative fieldwork but we may have missed other characteristics that could have been important to weigh in the enrollment decision. Including a larger number of levels for the premium compared to other attributes may have also introduced a level effect, although this would equally affect both household size groups. Moreover, the design included ranges for communication frequency which could have benefitted from greater balance and specificity. In addition, differences in group characteristics, namely the younger and wealthier respondents of small households and additional unobserved qualities, could have influenced both the scale and preferences. We present results without an optout to represent overall preferences of community members irrespective of whether they may purchase the insurance. Finally, dose-response relationships of household size could not be assessed in this study design.

Despite these limitations, this study importantly adds to the literature on preferences for health insurance in a lowincome country and describes the significance of controlling for scale when examining preference differences across groups. In fact, observed differences in stated preferences may be due to scale, or variance differences between groups, rather than true variations in preference. We found that coverage of hospital fees, travel and meal costs are given significant weight in CBHI enrollment decisions beyond the premium price, regardless of household size. Understanding how individuals make decisions 
about health insurance can inform countries' paths towards universal health coverage.

Acknowledgments We thank the Center for Advanced Study (CAS) in Cambodia for data collection efforts, especially Sovuthikar Inuong who led the group, and data collectors Ou Sirren, Ek Bunthorn, Touch Vannarath, and Van Sodaneath. We also thank the Cambodian Association for Assistance to Families and Widows (CAAFW) for the local support.

\section{Compliance with Ethical Standards}

No external funding was received for this study. SO, SG and JB declare no conflicts of interest. The study was approved by the Institutional Review Boards of Johns Hopkins School of Public Health and the National Ethics Committee for Health Research in Cambodia and was performed in accordance with the ethical standards of the Declaration of Helsinki. Informed consent was obtained from all individual participants included in the study.

Author contributions SO conceived and designed the study, developed the data collection instruments, and led the data collection efforts. All authors were involved in the data analysis and manuscript writing, and have approved the final version.

Open Access This article is distributed under the terms of the Creative Commons Attribution-NonCommercial 4.0 International License (http://creativecommons.org/licenses/by-nc/4.0/), which permits any noncommercial use, distribution, and reproduction in any medium, provided you give appropriate credit to the original author(s) and the source, provide a link to the Creative Commons license, and indicate if changes were made.

\section{References}

1. Carrin G, Waelkens MP, Criel B. Community-based health insurance in developing countries: a study of its contribution to the performance of health financing systems. Trop Med Int Health. 2005;10(8):799-811. doi:10.1111/j.1365-3156.2005. 01455.x.

2. Soors W, Devadasan N, Varatharajan D, Criel B. Community health insurance and universal coverage: multiple paths, many rivers to cross. Geneva: World Health Organization; 2010.

3. Jacobs B, Bigdeli M, van Pelt M, Ir P, Salze C, Criel B. Bridging community-based health insurance and social protection for health care-a step in the direction of universal coverage? Trop Med Int Health. 2008;13(2):140-3. doi:10.1111/j.1365-3156. 2007.01983.x.

4. Jehu-Appiah C, Aryeetey G, Spaan E, de Hoop T, Agyepong I, Baltussen R. Equity aspects of the National Health Insurance Scheme in Ghana: Who is enrolling, who is not and why? Soc Sci Med. 2011;72(2):157-65. doi:10.1016/j.socscimed.2010.10.025.

5. Olaniyan O, Sunkanmi OA. Demand for child healthcare in Nigeria. Global J Health Sci. 2012;4(6):129-40. doi:10.5539/ gjhs.v4n6p129.

6. De Allegri M, Sanon M, Bridges J, Sauerborn R. Understanding consumers' preferences and decision to enrol in communitybased health insurance in rural West Africa. Health Policy. 2006;76(1):58-71. doi:10.1016/j.healthpol.2005.04.010.

7. Dong H, De Allegri M, Gnawali D, Souares A, Sauerborn R. Drop-out analysis of community-based health insurance membership at Nouna, Burkina Faso. Health Policy. 2009;92(2-3):174-9. doi:10.1016/j.healthpol.2009.03.013.
8. Dong H, Gbangou A, De Allegri M, Pokhrel S, Sauerborn R. The differences in characteristics between health-care users and nonusers: implication for introducing community-based health insurance in Burkina Faso. Eur J Health Econ. 2008;9(1):41-50. doi:10.1007/s10198-006-0031-4.

9. Goudge J, Akazili J, Ataguba J, Kuwawenaruwa A, Borghi J, Harris B, et al. Social solidarity and willingness to tolerate riskand income-related cross-subsidies within health insurance: experiences from Ghana, Tanzania and South Africa. Health Policy Plan. 2012;27(Suppl 1):i55-63. doi:10.1093/heapol/ czs008.

10. Mladovsky P, Soors W, Ndiaye P, Ndiaye A, Criel B. Can social capital help explain enrolment (or lack thereof) in communitybased health insurance? Results of an exploratory mixed methods study from Senegal. Soc Sci Med. 2014;101:18-27. doi:10.1016/ j.socscimed.2013.11.016.

11. Basaza R, Criel B, Van der Stuyft P. Community health insurance in Uganda: why does enrolment remain low? A view from beneath. Health Policy. 2008;87(2):172-84. doi:10.1016/j. healthpol.2007.12.008.

12. Weismann D, Jutting J. The emerging movement of community based health insurance in Sub-Saharan Africa: experiences and lessons learned. Afr Spectr. 2000;35(2):1-19.

13. Savadogo G, Souares A, Sie A, Parmar D, Bibeau G, Sauerborn R. Using a community-based definition of poverty for targeting poor households for premium subsidies in the context of a community health insurance in Burkina Faso. BMC Public Health. 2015;15:84. doi:10.1186/s12889-014-1335-4.

14. Aryeetey GC, Jehu-Appiah C, Kotoh AM, Spaan E, Arhinful DK, Baltussen R, et al. Community concepts of poverty: an application to premium exemptions in Ghana's National Health Insurance Scheme. Glob Health. 2013;9:12. doi:10.1186/1744-8603-912.

15. Annear PL, Bigdeli M, Jacobs B. A functional model for monitoring equity and effectiveness in purchasing health insurance premiums for the poor: evidence from Cambodia and the Lao PDR. Health Policy. 2011;102(2-3):295-303. doi:10.1016/j. healthpol.2011.03.005.

16. Adebayo EF, Ataguba JE, Uthman OA, Okwundu CI, Lamont KT, Wiysonge CS. Factors that affect the uptake of communitybased health insurance in low-income and middle-income countries: a systematic protocol. BMJ Open. 2014;4(2):e004167. doi:10.1136/bmjopen-2013-004167.

17. Donfouet HP, Mahieu PA. Community-based health insurance and social capital: a review. Health Econ Rev. 2012;2(1):5. doi:10.1186/2191-1991-2-5.

18. Amaghionyeodiwe LA. Determinants of the choice of health care provider in Nigeria. Health Care Manag Sci. 2008;11(3):215-27.

19. Abiiro GA, Torbica A, Kwalamasa K, De Allegri M. Eliciting community preferences for complementary micro health insurance: a discrete choice experiment in rural Malawi. Soc Sci Med. 2014;120:160-8. doi:10.1016/j.socscimed.2014.09.021.

20. Van Damme W, Van Leemput L, Por I, Hardeman W, Meessen B. Out-of-pocket health expenditure and debt in poor households: evidence from Cambodia. Trop Med Int Health. 2004;9(2):273-80.

21. Khun S, Manderson L. Poverty, user fees and ability to pay for health care for children with suspected dengue in rural Cambodia. Int J Equity Health. 2008;7:10. doi:10.1186/1475-9276-7-10.

22. World Health Organization. Global Health Expenditure Database, National Health Account: Cambodia. In: Organization WH, editor. Geneva, Switzerland2012.

23. World Bank. World Development Indicators, Poverty headcount ratio at $\$ 2$ a day (PPP) as \% of population [Internet]. Washington DC: World Bank; [cited 2015 April 15]. Available from http:// 
data.worldbank.org/data-catalog/world-development-indicators/ wdi-2014.

24. Ozawa S, Walker DG. Trust in the context of community-based health insurance schemes in Cambodia: villagers' trust in health insurers. Adv Health Econ Health Serv Res. 2009;21:107-32.

25. Ir P, Bigdeli M, Meessen B, Van Damme W. Translating knowledge into policy and action to promote health equity: the Health Equity Fund policy process in Cambodia 2000-2008. Health Policy. 2010;96(3):200-9. doi:10.1016/j.healthpol.2010. 02.003 .

26. Center for Health Market Innovations. Cambodian Association for the Assistance to Families and Widows Community Health Insurance. Washington, D.C.: Results for Development Institute; 2012.

27. Bridges JF, Hauber AB, Marshall D, Lloyd A, Prosser LA, Regier DA, et al. Conjoint analysis applications in health-a checklist: a report of the ISPOR Good Research Practices for Conjoint Analysis Task Force. Value Health. 2011;14(4):403-13. doi:10. 1016/j.jval.2010.11.013.

28. de Bekker-Grob EW, Ryan M, Gerard K. Discrete choice experiments in health economics: a review of the literature. Health Econ. 2012;21(2):145-72. doi:10.1002/hec.1697.

29. Abiiro GA, Leppert G, Mbera GB, Robyn PJ, De Allegri M. Developing attributes and attribute-levels for a discrete choice experiment on micro health insurance in rural Malawi. BMC Health Serv Res. 2014;14:235. doi:10.1186/1472-6963-14-235.

30. van den Berg B, Van Dommelen P, Stam P, Laske-Aldershof T, Buchmueller T, Schut FT. Preferences and choices for care and health insurance. Soc Sci Med. 2008;66(12):2448-59. doi:10. 1016/j.socscimed.2008.02.021.

31. Becker K, Zweifel P. Age and choice in health insurance: evidence from a discrete choice experiment. Patient. 2008;1(1):27-40.

32. Vroomen J, Zweifel P. Preferences for health insurance and health status: does it matter whether you are Dutch or German? Eur J Health Econ. 2011;12(1):87-95.

33. Trujillo AJ, Ruiz F, Bridges JF, Amaya JL, Buttorff C, Quiroga AM. Understanding consumer preferences in the context of managed competition: evidence from a choice experiment in
Colombia. Appl Health Econ Health Policy. 2012;10(2):99-111. doi:10.2165/11594820-000000000-00000.

34. Chakraborty G, Ettenson R, Gaeth G. How consumers choose health insurance. J Health Care Mark. 1994;14(1):21-33.

35. Kerssens JJ, Groenewegen PP. Consumer preferences in social health insurance. Eur J Health Econ. 2005;6(1):8-15. doi:10. 1007/s10198-004-0252-3.

36. Telser $\mathrm{H}$, Zweifel $\mathrm{P}$. Measuring willingness-to-pay for risk reduction: an application of conjoint analysis. Health Econ. 2002;11(2):129-39.

37. Swait J, Louviere JJ. The role of the scale parameter in the estimation and comparison of multinomial logit models. J Mark Res. 1993;30(3):305-14.

38. Ozawa S, Walker DG. Comparison of trust in public vs private health care providers in rural Cambodia. Health Policy Plan. 2011;26(Suppl 1):i20-9. doi:10.1093/heapol/czr045.

39. Ozawa S, Walker DG. Villagers' evaluation of a communitybased health insurance scheme in Thmar Pouk, Cambodia. Improving health sector performance: institutions, motivations and incentives - the Cambodian Dialogue. Singapore: Institute of Southeast Asian Studies; 2011.

40. Johnson FR, Lancsar E, Marshall D, et al. Constructing experimental designs for discrete-choice experiments: report of the ISPOR conjoint analysis discrete-choice experiment experimental design good research practices task force. Value Health. 2013;16:3-13.

41. Marshall D, Bridges $\mathrm{J}$, Hauber $\mathrm{AB}$, et al. Conjoint analysis applications in health-how are studies being designed and reported? An update on current practice in the published literature between 2005 and 2008. Patient. 2010;3:249-56.

42. Manski CF. The structure of random utility models. Decis Theory. 1977;8:229-54.

43. McFadden D. Conditional logit analysis of qualitative choice behavior. Frontiers in econometrics. New York: Academic Press; 1974.

44. Flynn TN, Louviere JJ, Peters TJ, Coast J. Using discrete choice experiments to understand preferences for quality of life. Variance-scale heterogeneity matters. Soc Sci Med. 2010;70(12):1957-65. doi:10.1016/j.socscimed.2010.03.008. 